\title{
ANALISIS RENCANA KEBUTUHAN ALAT GALI-MUAT EXCAVATOR CATERPILLAR 320D2 DAN EXCAVATOR KOBELCO SK330 TERHADAP ALAT ANGKUT DUMP TRUCK HINO 500 FM260JD PADA KEGIATAN PENAMBANGAN BIJIH NIKEL
}

\author{
Siti Indah Rachmadiani ${ }^{1 *}$, Anton Sudiyanto ${ }^{1}$, Tedy Agung Cahyadi ${ }^{1}$, Inmarlinianto ${ }^{1}$, \\ Winda $^{1}$, Darwis ${ }^{2}$ \\ ${ }^{1}$ Program Studi Sarjana Teknik Pertambangan, Universitas Pembangunan Nasional "Veteran" Yogyakarta \\ ${ }^{2}$ PT. Jaya Bersama Sahabat, Kabupaten Konawe Utara, Sulawesi Tenggara
}

\author{
* Corresponding author : rachmadianisitiindah@gmail.com \\ Received: Nov 22, 2021; Accepted: Dec 25, 2021. \\ DOI: https://doi.org/10.31764/jpl.v2i2.6149
}

\begin{abstract}
Abstrak. PT. Jaya Bersama Sahabat merupakan perusahaan pertambangan bijih nikel yang terletak di Kabupaten Konawe Utara, Provinsi Sulawesi Tenggara. Penelitian ini bertujuan untuk menghitung produktivitas alat gali-muat dan alat angkut, menghitung jumlah alat gali-muat dan alat angkut yang dibutuhkan serta menghitung faktor keserasian kerja dari masing-masing kombinasi kerja alat mekanis. Metode dalam penelitian ini dilakukan melalui beberapa tahapan yaitu pengamatan fakta perusahaan, identifikasi masalah, studi literature, pengamatan di lapangan, pengambilan data berupa data primer dan sekunder, perumusan, pengelolaan dan analisis data. Produktivitas kombinasi kerja antara Excavator Caterpillar 320D2 dengan Dump Truck Hino 500 FM260JD yaitu 2249,22 ton/hari untuk excavator dan 202,07 ton/hari untuk dump truck sedangkan produktivitas kombinasi kerja antara Excavator Kobelco SK330 dengan Dump Truck Hino 500 FM260 JD adalah 4058,17 ton/hari untuk excavator dan 263,57 ton/hari untuk dump truck. Jumlah kebutuhan alat mekanis yang dibutuhkan untuk mencapai target produksi yaitu 2 (dua) unit excavator dan 13 unit dump truck jika menggunakan kombinasi kerja antara Excavator Caterpillar 320D2 dengan Dump Truck Hino 500 FM260JD dengan memiliki faktor keserasian kerja sebesar 0,62 dan jika menggunakan kombinasi kerja antara Excavator Kobelco SK330 dengan Dump Truck Hino 500 FM260JD maka dibutuhkan 1 unit excavator dan 10 unit dump truck dengan faktor keserasian kerja sebesar 0,69.
\end{abstract}

Kata Kunci: produktivitas, excavator, dump truck.

\begin{abstract}
PT. Jaya Bersama Sahabat is a nickel mining company located in North Konawe Regency, Southeast Sulawesi Province. This study aims to find the productivity of loading and hauling equipment, to find the number of loading and hauling equipment and to calculate the match factor of each combination of mechanical equipments. The method used in this study was carried out through several stages, which are observing company facts, problem identification, literature study, field observations, data collection in the form of primary and secondary data, formulation, processing and data analysis. The productivity of the work combination between Caterpillar 320D2 Excavator and Hino 500 FM260JD Dump Truck is 2249,22 ton/day for the exvavator and 202,07 ton/day for the dump truck, while the combined productivity of Kobelco SK330 and Hino 500 FM260JD Dump Truck is 4058,17 ton/day for the excavator and 263,57 ton/day for dump truck. The number of mechanical equipment needed to achieve the production target is 2 excavators and 13 dump trucks if use a work combination between Caterpillar 320D2 Excavator and Hino 500 FM260JD Dump Truck with a match factor of 0,62. And if use a work combination between Kobelco SK330 Excavator with Hino 500 FM260JD Dump Truck are needed with a match factor of 0,69.
\end{abstract}

Keywords: productivity, excavator, dump truck 


\section{Pendahuluan}

Perencanaan tambang merupakan tahapan penting dalam studi kelayakan dan rencana kegiatan penambangan mineral dan batubara (Bargawa, 2018). Kegiatan penambangan terdiri dari kegiatan pembongkaran, pemuatan, dan pengangkutan. Pengelolaan operasi tambang yang tepat diperlukan untuk meminimalkan dampak negatif dan mengingkatkan hasil yang positif. Salah satu pengelolaan tambang yang perlu diperhatikan adalah pengelolaan alat mekanis (Adiansyah, et al., 2017).

PT. Jaya Bersama Sahabat merupakan salah satu perusahaan yang bergerak di industri pertambangan untuk komoditas bijih nikel yang terletak di Desa Waturambaha, Kecamatan Lasolo Kepulauan, Kabupaten Konawe Utara, Provinsi Sulawesi Tenggara dengan sistem tambang terbuka (surface mining) dan memiliki target produksi sebesar 75.000 ton/bulan (Gambar 1). Kegiatan utama pada penambangan tersebut adalah pembongkaran, pemuatan dan pengangkutan material dari loading point menuju dumping point. Agar target produksi pada penambangan bijih nikel di perusahaan ini dapat tercapai, maka perlu dilakukan perhitungan kebutuhan jumlah alat gali-muat dan alat angkut yang digunakan dalam kegiatan pemuatan dan pengangkutan dengan jenis alat yaitu Excavator Caterpillar 320D2 dan Excavator Kobelco SK330 terhadap Dump Truck Hino 500 FM260JD.

Tujuan dilakukannya penelitian ini yaitu menghitung produktivitas alat gali-muat dan alat angkut yang digunakan, menghitung jumlah alat gali-muat dan alat angkut, dan perlu dilakukan perhitungan keserasian kerja antar kombinasi alat gali-muat Excavator Caterpillar 320D2 dan Excavator Kobelco SK330 terhadap Dump Truck Hino 500 FM260JD.

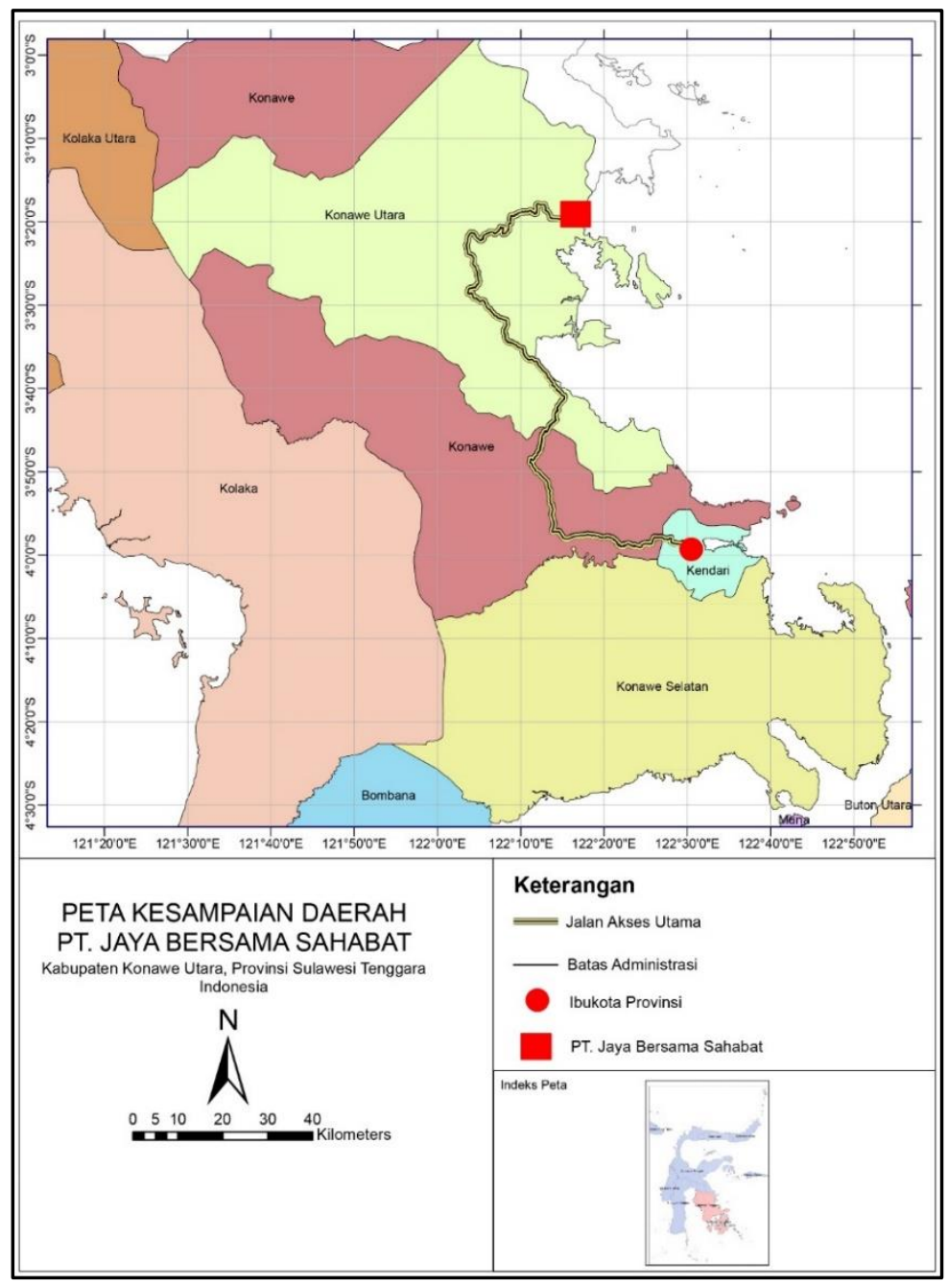

Gambar 1. Peta Kesampaian Daerah PT. Jaya Bersama Sahabat Fig 1. Area Achievement Map of PT. Jaya Bersama Sahabat 


\section{Metode Penelitian}

Penelitian ini dilakukan dari tanggal 23 Juli sampai dengan 9 Oktober 2020 dan melalui beberapa tahapan yaitu pengamatan fakta perusahaan, identifikasi masalah, studi literatur, pengamatan dilapangan, pengambilan data berupa data primer dan sekunder, perumusan, pengolahan dan analisis data (Gambar 2).

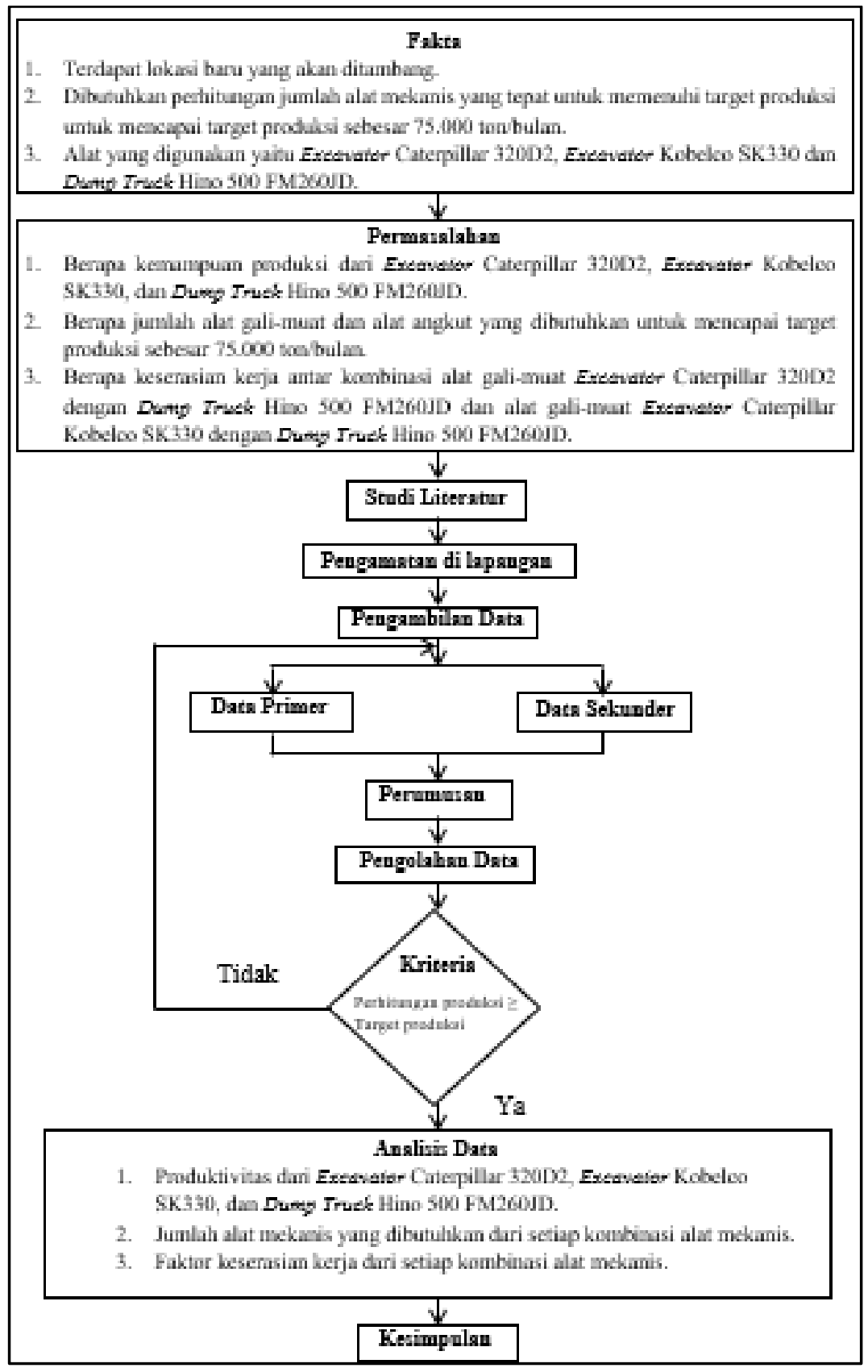

Gambar 2. Diagram Alir Tahapan Penelitian

Fig 2. Research Flow Chart

Pola pemuatan berdasarkan dari posisi alat angkut saat dimuati alat gali-muat (Gambar 3), yaitu top loading dan bottom loading. Top loading yaitu kedudukan alat gali-muat lebih tinggi dari alat angkut (alat gali-muat berada diatas jenjang dan alat angkut berada dijenjang bawah), sedangkan bottom loading yaitu kedudukan alat gali-muat dan alat angkut berada pada jenjang atau level yang sama. Berdasarkan dari jumlah penempatan posisi alat angkut untuk dimuati terhadap posisi alat galimuat, maka ada dua macam pola pemuatan yaitu single back up dan double back up (Gambar 4). Pola pemuatan single back up yaitu alat angkut pertama memposisikan untuk dimuati sedangkan alat angkut berikutnya menunggu alat angkut pertama dimuati sampai penuh, setelah alat angkut pertama 
berangkat, alat angkut kedua memposisikan diri untuk dimuati sedangkan alat angkut ketiga menunggu dan begitu seterusnya. Pola pemuatan double back up yaitu Alat angkut pertama dan kedua memposisikan diri pada dua tempat kemudian alat gali-muat mengisi alat angkut pertama sampai penuh, kemudian alat angkut pertama berangkat, sementara alat angkut kedua dimuati material, alat angkut ketiga memposisikan diri untuk dimuati dan begitu seterusnya.

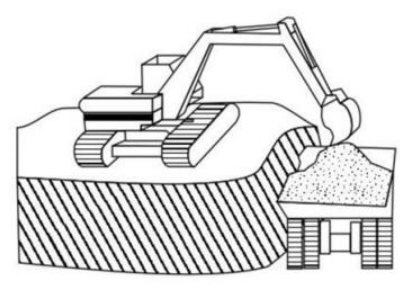

a. Top Loading

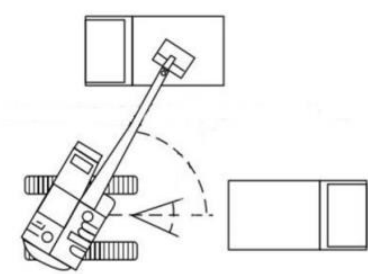

b. Bottom Loading

Gambar 3. Pola Top Loading dan Bottom Loading (Helbert, 1955).

Fig 3. Top Loading and Bottom Loading Methods (Helbert, 1955).

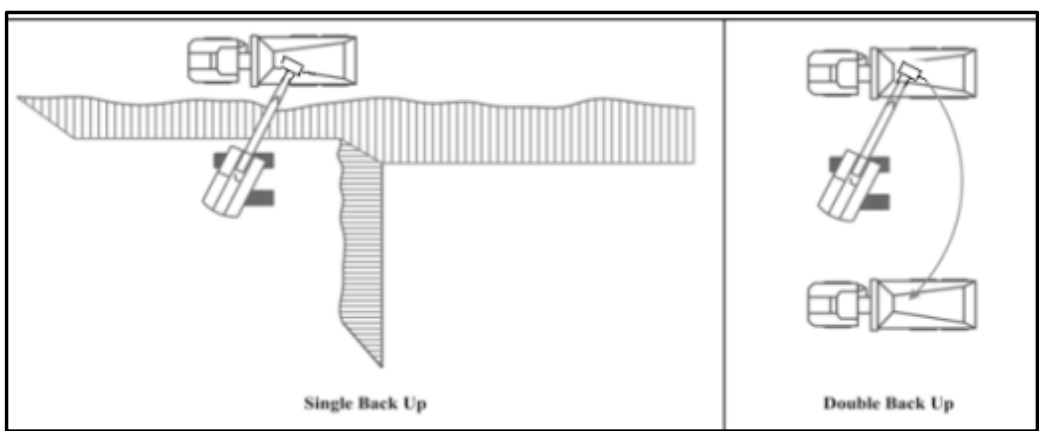

Gambar 4. Pola Single Back Up dan Double Back Up (Helbert, 1955).

Fig 4. Single Back Up and Double Back Up (Helbert, 1955).

Pada pengolahan data dibutuhkan rumus perhitungan untuk memperoleh hasil yang tepat. Berikut rumus perhitungan yang digunakan:

\section{a. Waktu edar alat gali-muat dan alat angkut}

Waktu edar alat gali-muat dapat dicari dengan menjumlahkan waktu untuk mengisi mangkuk, waktu memutar dengan mangkuk bermuatan, waktu untuk menumpahkan muatan, waktu memutar dengan mangkuk kosong (persamaan (1)) sedangkan waktu edar alat angkut dapat dicari dengan menjumlahkan waktu mengatur posisi siap dimuati, waktu pengisian, waktu mengangkut muatan, waktu mengatur posisi untuk menumpahkan muatan, waktu mengatur posisi untuk menumpahkan muatan, waktu menumpahkan muatan, waktu kembali kosong (persamaan (2)) (Indonesianto, 2019).

$$
\begin{aligned}
& C T_{m}=T_{m 1}+T_{m 2}+T_{m 3}+T_{m 4} \\
& C T_{a}=T_{a 1}+T_{a 2}+T_{a 3}+T_{a 4}+T_{a 5}+T_{a 6}
\end{aligned}
$$

\section{b. Faktor pengembangan (swell factor)}

Faktor pengembangan merupakan pengembangan volume suatu material setelah digali dari tempat aslinya dan dapat dicari dengan membagi densitas dalam keadaan asli ( $p$ bank) dengan densitas dalam keadaan lepas ( $p$ loose) atau dapat dilihat pada persamaan (3) (Peurifoy, 1988).

$$
S f=\frac{p \text { loose }}{p \text { bank }}
$$

\section{c. Faktor Pengisian Mangkuk (Bucket Fill Factor)}

Faktor pengisian mangkuk merupakan perbandingan antara volume nyata mangkuk alat gali-muat $\left(V_{n}\right)$ dengan volume teoritis mangkuk alat gali-muat $\left(V_{d}\right)$ dan dapat dihitung menggunakan persamaan (4) (Eugene, 1992). 


$$
B f f=\frac{V_{n}}{V_{d}} \times 100 \%
$$

\section{d. Efisiensi Kerja}

Efisiensi kerja diperoleh dari perbandingan antara waktu kerja efektif dengan waktu kerja yang tersedia dan dapat dihitung menggunakan persamaan (5).

$$
E k=\frac{W_{e}}{W_{t}} \times 100 \%
$$

\section{e. Produktivitas Alat Gali-Muat dan Alat Angkut}

Komponen-komponen yang berpengaruh terhadap perhitungan produktivitas alat gali-muat dan alat angkut yaitu waktu edar $(C T)$, kapasitas mangkuk $(C b)$, faktor pengisian mangkuk $(B f f)$, faktor pengembangan $(S f)$, efisiensi kerja $(E k)$ dan densitas dalam keadaan asli $\left(D_{\text {insitu }}\right)$. Untuk menghitung produktivitas alat gali-muat menggunakan persamaan (6) dan untuk menghitung produktivitas alat angkut menggunakan persamaan (7).

$$
\begin{aligned}
& P_{m}=\frac{3600}{C T_{m}} \times C b \times B f f \times S f \times E k \times D_{\text {insitu }} \\
& P_{a}=\frac{3600}{C T_{a}} \times C b \times n \times B f f \times S f \times E k \times D_{\text {insitu }}
\end{aligned}
$$

\section{f. Jumlah Alat Gali-Muat dan Alat Angkut yang Dibutuhkan}

Untuk menghitung jumlah alat gali-muat dan alat angkut dapat dilakukan dengan membagi produktivitas alat mekanis $(P)$ dengan target produksi $(T)$ yang telah ditetapkan (Persamaan (8)).

$$
N=\frac{T}{P}
$$

\section{g. Faktor Keserasian Kerja (Match Factor)}

Faktor keserasian kerja digunakan untuk menilai keserasian kerja antara dua alat mekanis yaitu alat gali-muat dan alat angkut. Nilai faktor keserasian kerja yang baik adalah 1, karena menunjukkan bahwa kemampuan produksi alat gali-muat sama dengan kemampuan produksi alat angkut. Komponen-komponen yang diperlukan dalam menghitung faktor keserasian kerja yaitu jumlah alat angkut $\left(N_{a}\right)$, jumlah alat gali-muat $\left(N_{m}\right)$, jumlah curah $(n)$, waktu edar alat gali-muat $\left(C T_{m}\right)$, waktu edar alat angkut $\left(C T_{a}\right)$. Untuk menghitung faktor keserasian kerja dapat menggunakan persamaan (9).

$$
M F=\frac{N_{a} \times n \times C T_{m}}{N_{m} \times C T_{a}}
$$

\section{Hasil dan Pembahasan}

Perencanaan kebutuhan alat gali-muat dan alat angkut dilakukan untuk menghitungan jumlah alat mekanis yang digunakan untuk mencapai target produksi yaitu sebesar 75.000 ton/bulan. PT. Jaya Bersama Sahabat menggunakan alat gali-muat Excavator Caterpillar 320D2 dan Excavator Kobelco SK330, sedangkan alat angkut yang digunakan yaitu Dump Truck Hino 500 FM260JD. Komponen-komponen yang diperhatikan agar target produksi tercapai yaitu produktivitas alat galimuat dan alat angkut, jumlah alat gali-muat dan alat angkut yang digunakan dan juga faktor keserasian kerja alat alat gali-muat dan alat angkut.

\subsection{Produktivitas Alat Gali-Muat dan Alat Angkut}

Produktivitas alat gali-muat dan alat angkut dapat digunakan untuk menilai kinerja dari alat galimuat dan alat angkut. Semakin baik tingkat penggunaan alat mekanis tersebut maka semakin besar produksi yang dihasilkan, sedangkan jika tingkat penggunaan alatnya buruk maka besar produksi juga tidak akan terlalu baik. Beberapa faktor yang mempengaruhi produktivitas alat mekanis yaitu waktu edar (cycle time) alat gali-muat dan alat angkut, kapasitas mangkuk alat gali-muat, jumlah curah mangkuk pada kegiatas pemuatan, faktor pengembangan (swell factor), faktor pengisian mangkuk (bucket fill factor), efisiensi kerja alat gali-muat dan alat angkut. Hasil yang diperoleh dari pengolahan data mengenai faktor produktivitas alat gali-muat dan alat angkut dapat dilihat pada Tabel 1 dan Tabel 2. 
Waktu edar dari alat gali-muat dan alat angkut dipengaruhi oleh beberapa faktor yaitu pola pemuatan, kondisi tempat kerja, dan kemampuan atau keahlian operator. Pola pemuatan yang diterapkan di PT. Jaya Bersama Sahabat yaitu pola pemuatan top loading dan single back up, pola pemuatan ini sudah tepat karena dapat memperkecil waktu edar alat mekanis yang digunakan. pada saat musim kemarau, kondisi tempat kerja berdebu sehingga dapat membatasi jarak pandang dari operator sedangkan pada musim penghujan kondisi tempat kerja akan licin dan berlumpur sehingga operator harus mengurangi kecepatan dan lebih berhati-hati. Operator yang berpengalaman dan memiliki keahlian dapat memperkecil waktu edar.

Tabel 1. Komponen Produktivitas Alat Gali-Muat

Table 1. Excavator Productivity Components

\begin{tabular}{lcc}
\hline & Excavator Caterpillar 320D2 & Excavator Kobelco SK330 \\
\hline Waktu edar (CT) & 17,2 detik & 21 detik \\
Kapasitas mangkuk $(\mathrm{Cb})$ & $0,9 \mathrm{~m}^{3}$ & $1,6 \mathrm{~m}^{3}$ \\
Jumlah curah (n) & $10 \mathrm{curah}$ & $6 \mathrm{curah}$ \\
Faktor pengisian mangkuk (Bff) & $92,11 \%$ & $114,25 \%$ \\
Faktor pengembangan (Sf) & 0,97 & 0,97 \\
Efisiensi kerja (Ek) & $77,57 \%$ & $77,57 \%$ \\
\hline
\end{tabular}

Tabel 2. Komponen Produktivitas Alat Angkut

Table 2. Dump Truck Productivity Components

\begin{tabular}{lcc}
\hline & \multicolumn{2}{c}{ Dump Truck Hino 500 FM260JD } \\
\cline { 2 - 3 } & Excavator Caterpillar 320D2 & Excavator Kobelco SK330 \\
\hline Waktu edar (CT) & 1808,47 detik & 1832,1 detik \\
Efisiensi kerja (Ek) & $75,19 \%$ & $75,19 \%$ \\
\hline
\end{tabular}

Dari hasil pengolahan data diperoleh produktivitas Excavator Caterpillar 320D2 sebesar 2249,22 ton/hari sedangkan produktivitas Excavator Kobelco SK330 sebesar 4058,17 ton/hari. Untuk produktivitas alat angkut Dump Truck Hino 500 FM260JD terhadap Excavator Caterpillar 320D2 adalah sebesar 202,07 ton/hari sedangkan produktivitas Dump Truck Hino 500 FM260JD terhadap Excavator Kobelco SK330 sebesar 263,57 ton/hari.

\subsection{Kebutuhan Alat Gali-Muat dan Alat Angkut}

Untuk mencapai target produksi yang telah ditetapkan maka diperlukan perhitungan jumlah alat gali-muat dan alat angkut yang tepat pada kegiatan pemuatan dan pengangkutan. Jumlah alat galimuat dan alat angkut yang dibutuhkan untuk mencapai target produksi sebesar 75.000 ton/bulan atau 2.500 ton/hari yaitu 2 (dua) unit alat gali-muat dan 13 unit alat angkut, jika menggunakan kombinasi kerja antara Excavator Caterpillar 320D2 dengan Dump Truck Hino 500 FM260JD. Apabila yang digunakan adalah kombinasi kerja antara Excavator Kobelco SK330 dengan Dump Truck Hino 500 FM260JD maka alat mekanis yang dibutuhkan yaitu 1(satu) unit alat gali-muat dan 10 unit alat angkut.

\subsection{Faktor Keserasian Kerja (Match Factor)}

Faktor keserasian kerja yang diperoleh dari hasil perhitungan yaitu 0,62 untuk kombinasi kerja antara Excavator Caterpillar 320D2 dengan Dump Truck Hino 500 FM260JD, sedangkan untuk kombinasi kerja antara Excavator Kobelco SK3330 dengan Dump Truck Hino 500 FM260JD yaitu 0,69. Kedua kombinasi kerja alat mekanis tersebut memiliki selisih 0,07. Nilai match factor kurang 
dari 1 menandakan bahwa produktivitas alat gali-muat lebih besar daripada produktivitas alat angkut, maka terdapat waktu tunggu pada alat gali-muat.

\section{Kesimpulan}

Dari hasil penelitian yang dilakukan di PT. Jaya Bersama Sahabat dari 23 Juli sampai 9 Oktober 2020 dapat ditarik kesimpulan bahwa produktivitas kombinasi kerja antara Excavator Caterpillar 320D2 dengan Dump Truck Hino 500 FM260JD yaitu 2249,22 ton/hari untuk alat gali-muat dan 202,07 ton/hari untuk alat angkut. Produktivitas kombinasi kerja antara Excavator Kobelco SK330 dengan Dump Truck Hino 500 FM260JD yaitu 4058,17 ton/hari untuk alat gali-muat dan 263,57 ton/hari untuk alat angkut. Jumlah alat yang dibutuhkan untuk mencapai target produksi sebesar 75.000 ton/bulan yaitu 2 unit Excavator Caterpillar 320D2 dengan 13 unit Dump Truck Hino 500 FM260JD dengan faktor keserasian kerja sebesar 0,62, sedangkan jika menggunakan Excavator Kobelco SK330 dengan Dump Truck Hino 500 FM260JD maka dibutuhkan 1 unit alat gali-muat dan 10 unit alat angkut dengan faktor keserasian kerja sebesar 0,69.

\section{Referensi}

Adiansyah, J. S., Payadi, K., Alpiana \& Rahmawati, D., 2017. Evaluation of Loading and Hauling Technology for Improving Andesite Mine Performance. IOP COnference Series: Materials Science and Engineering, 403((2018) 012048), pp. 1-4.

Bargawa, W. S., 2018. Perencanaan Tambang. 8 ed. Yogyakarta: Kilau Book.

Eugene, P. P., 1992. Surface Mining. 1 ed. New York: USA: The American Institute of Mining.

Helbert, L. N., 1955. Moving the Earth: The Workbook of Excavation, 1 ed. USA: North Castle Books.

Indonesianto, Y., 2019. Pemindahan Tanah Mekanis. 1 ed. Yogyakarta: Program Studi Teknik Pertambangan Institut Teknologi Yogyakarta.

Peurifoy, R. L., 1988. COnstruction Planning Equipment and Method. 7 ed. New York: USA: McGraw-Hill Education. 